\title{
Competencias de Redacción en Estudiantes de Derecho de una Universidad Pública Peruana
}

\section{Writing Competences in Law Students of a Peruvian Public University}

\author{
Wuilber Jorge Alca Robles ${ }^{1}$, Abdías Chávez Epiquén ${ }^{2}$ y Frank Bollet Ramírez ${ }^{3}$ \\ ${ }^{1}$ Facultad de Derecho y Ciencia Política, Universidad Nacional Mayor de San Marcos, war_alca@hotmail.com, \\ ORCID: https://orcid.org/0000-0001-6595-5391 \\ ${ }^{2}$ Facultad de Ciencias Empresariales, Universidad Nacional Ciro Alegría, achavez@unca.edu.pe, ORCID: \\ https://orcid.org/0000-0001-5589-5217 \\ 3 Facultad de Ciencias Económicas, Administrativas y Contables, Universidad Nacional de Ucayali, \\ frankbollet@hotmail.com, ORCID: https://orcid.org/0000-0002-4670-8114
}

\section{Resumen}

La investigación tuvo como objetivo, determinar la relación entre las competencias de redacción científica, y la argumentación jurídica en los estudiantes del octavo y noveno ciclo y egresados de Derecho de la Universidad Nacional de San Martin año 2019 - 2020. Se trabajó con una muestra de 84 estudiantes del noveno al décimo ciclo de la carrera de derecho de la Universidad Nacional de San Martin; los datos fueron obtenidos con la técnica de la observación utilizando la guía de observación directa, valida y confiable. El estudio tiene un alcance de nivel descriptivo, diseño correlacional transversal. Se aplicó el método científico, método estadístico y el método inductivo deductivo, procediendo a observar el desempeño de los estudiantes para cada variable. Para la correlación se usó el coeficiente rho de Spearman con cuyos datos se hizo la prueba de hipótesis. Las conclusiones fue que no existe relación directa y significativa entre redacción científica y argumentación jurídica rho 0,195 de rho de Spearman al 0,05 de significancia.

Palabras clave: Argumentación jurídica; Escrito científico; Derecho.

\begin{abstract}
The objective of the research was to determine the relationship between scientific writing competencies and legal argumentation in students of the eighth and ninth cycle and law graduates of the National University of San Martin in the year 2019 - 2020. We worked with a sample of 84 students from the ninth to the tenth cycle of the law career at the National University of San Martin; the data were obtained with the observation technique using the direct, valid and reliable observation guide. The study has a descriptive-level scope of cross-sectional correlational design. The scientific method, statistical method and inductive deductive method were applied, proceeding to observe the performance of the students for each variable. Spearman's rho coefficient was used for correlation, with the data of which the hypothesis test was performed. The conclusions were that there is no direct and significant relationship between scientific writing and legal argumentation rho 0.195 of rho de Spearman at 0.05 of significance.
\end{abstract}

Keywords: Legal argumentation; Scientific writing; Law.

\section{Introducción}

La redacción científica es una habilidad especial para quienes realizan investigación y publican los resultados en medios de buena visibilidad, esta función se afianza potencialmente de un elemento clave de la producción intelectual; la argumentación. En la disciplina del Derecho se 
maximiza este criterio que busca evidenciar de mejor manera las habilidades de redacción científica y la argumentación jurídica, dado que el Derecho es una profesión eminentemente dialógica, en donde prima entre otras competencias, dialogo, argumentación y redacción en el marco democrático de tolerancia e intercambio de ideas. Esta disciplina se enfoca en la formación de los estudiantes de la carrera profesional de Derecho acorde con su perfil profesional, donde se debe lograr su formación como un abogado competente; que en el ejercicio de su labor actué con excelencia profesional e integridad moral.

Lo que se evidencia en la actualidad es una situación totalmente opuesta a los criterios ideales para un abogado a punto de concluir su carrera en cuanto a redacción científica y argumentación, contexto preocupante que se ha evidenciado en mayor medida con la generalización de la educación virtual producto de la pandemia y estado de emergencia nacional. Consultado a varios profesionales de derecho, docentes universitarios de esta disciplina, concordaron con la opinión de un gran sector de juristas y otros maestros docentes del Derecho, se advierte, que dicha realidad educativa universitaria evidencia una aguda $y$ permanente crisis lingüística y de conocimiento científico. Esta situación, progresivamente se viene agravando y que no es una simple observación o preocupación personal sino de amplio conocimiento, ya que diversos son los fueros académicos y en el propio ejercicio profesional, donde se han manifestado varias voces alertando sobre esa crisis en muchos estudiantes de derecho, egresados e incluso en abogados en ejercicio de nuestro país.

Basta con corroborar las deficiencias en su formación lingüística y científica existentes, ya que no pueden afrontar, analizar y resolver un problema de naturaleza jurídica bajo bases científicas, lingüísticas y comunicativas adecuadas e idóneas, no pudiendo identificar un problema, las herramientas jurídicas necesarias para su solución, que variables e indicadores en el ámbito del derecho se debieran aplicar, el plantear hipótesis jurídicas sin caer en falacias o el redactar enunciados y argumentos claros y concisos bajo una correcta sintaxis y paráfrasis, entre otros, muestras claras y concretas de la existencia de un progresivo analfabetismo científico y jurídico.

La interrogante surge, ¿Por qué relacionar la redacción científica con la argumentación jurídica? La respuesta nos lleva al análisis del perfil del egresado universitario en la carrera de Derecho, pues su formación no solamente se proyecta en desarrollar competencias de la especialidad, sino que debe ser un científico, la universidad le otorga una licencia no solo para ejercer la profesión sino para hacer ciencia acerca de su especialidad. Es la redacción científica la que le permite desarrollar 
competencias y habilidades de escritura, descripción, argumentación, sintaxis con especial afinidad.

El propósito de la investigación fue determinar el grado de relación que existe entre variables, redacción científica y argumentación jurídica en estudiantes del octavo y noveno ciclo de Derecho de la Universidad Nacional de San Martin Perú. Se considera que el estudiante universitario en la línea de lograr una mejor formación de calidad con transformación, se vincula en general con materias afines a la redacción y argumentación en el ámbito de sus competencias profesionales, ya que son elementos transversales a su propia formación universitaria y muy necesarios en el desarrollo de su etapa formativa como estudiante y a futuro como profesional en ejercicio.

En una revisión hecha por los años 2007 de la muestra de resoluciones judiciales proporcionadas por el Programa de Formación de Aspirantes (PROFA) de la Academia de la Magistratura, se pudo identificar las siguientes deficiencias a nivel de los rasgos de la argumentación y redacción de las referidas resoluciones judiciales, encontrando lo siguiente:

a. Cerca de la mitad de resoluciones cuentan con niveles satisfactorios de argumentación y redacción. El promedio obtenido en las evaluaciones va de 12 a 14 puntos sobre un total de 24. b. La otra mitad de las resoluciones cuenta con una puntuación entre los 15 y 18 puntos, lo que representa una medianía en la que ya se identifican fortalezas y debilidades.

c. Entre las fortalezas destacan la coherencia y la fuerza de la argumentación, que no reflejan mayores dificultades pues superan los 3 puntos sobre una escala de 0 a 4 .

d. Los problemas o debilidades más presentes son la falta de orden en el planteamiento de la redacción, una buena diagramación de los textos y la debilidad de la argumentación por insuficiencia o redundancia que se ubican en el rango de 2 puntos sobre una escala de 0 a 4 . Otra debilidad, siempre en el rango de 2 puntos, es la falta de claridad al expresar la argumentación. (León, 2008, p. 14)

Por su parte, el Consejo Nacional de la Magistratura en su Resolución No 120-2014PCNM, que constituye el primer precedente administrativo sobre evaluación de jueces y fiscales peruanos a nivel nacional, el Consejo reconocía haber acumulado en los últimos años experiencia en más de 1500 procesos de ratificación de magistrados, pero refiriendo que en base a la experiencia acumulada confirmaba según León (2016), los consejeros sostienen además que: 
Se deben evitar párrafos y argumentos redundantes, fórmulas de estilo o frases genéricas sin mayor relevancia en la solución del problema planteado; así como, la mera glosa o resumen de todas las pruebas practicadas en las fases del proceso, sin efectuar el razonamiento probatorio correspondiente.

Se ha observado que los magistrados redactan párrafos interminables que contienen argumentos distintos, y hasta contrapuestos, pero que solo se encuentran divididos por una coma. Ello hace difícil determinar cuál es la conexión de los argumentos y su relevancia para la toma de la decisión. Por tanto, una resolución de calidad, deberá ser correcta en lo referente al manejo del lenguaje escrito, así como en la coherencia de los enunciados que la conforman. (Pp.16-17)

\section{Metodología}

El estudio consistió en evaluar el desempeño de los estudiantes de los últimos ciclos sobre su capacidad de redacción, tanto en el curso de tesis como las asignaturas a cargo del docente de la especialidad de Derecho. La evaluación se hizo individualizado tomando los trabajos de redacción como producto del curso.

Metodológicamente, la investigación en cuanto a su finalidad se clasifica como básica teórica porque analiza los fundamentos teóricos de la redacción científica, redacción jurídica y argumentación jurídica describirla y buscar su correlación. Es un estudio de alcance descriptivo, con un diseño no experimental correlacional de corte transversal. La muestra se conformó de 84 estudiantes del octavo ciclo, noveno ciclo y egresados de Derecho de la Universidad Nacional de San Martin año 2019 - 2020, elegidas por decisión del investigador. Para la recolección de datos se usó la guía de observación Los resultados fueron procesados mediante el programa estadístico SPSS versión 25.

En la variable de estudio, redacción científica, es necesario analizar la concepción teórica, "La redacción científica es la transmisión de una señal clara al receptor, como sea posible; se caracteriza por una escritura precisa y concisa de artículos científicos, informe escrito, que comunica por primera vez los resultados de una investigación y relativamente corto y se publica en una revista científica o libro". (Mut, 2010).

Rojas (2006) sostiene que la Redacción Científica es: "una importantísima herramienta en la publicación de la ciencia. Una proporción desconocida de nuevos conocimientos que no llegan a la intelectualidad científica, se debe a una también tasa desconocida, de fracasos de candidatos a los Grados académicos" (Bachilleres, Magísteres o Doctores). 
La redacción científica es la transmisión de una señal clara al receptor.

"Las palabras de esa señal deben ser tan claras, sencillas y ordenadas como sea posible. La redacción científica no tiene necesidad de adornos ni cabida para ellos. Es muy probable que los adornos literarios floridos, las metáforas, los símiles y las expresiones idiomáticas induzcan a confusión, por lo que rara vez deben utilizarse al redactar artículos de investigación" (Mut, 2010)

Referente a la argumentación, al decir de Wagner (2015), los orígenes de la teoría de la argumentación se remontan a Aristóteles (384322 A.C.), quien afirmó en sus posturas Sofísticas que en lo concerniente al estudio del razonamiento y de la argumentación como pionero del mismo no existía nada antes de él, sentando sus bases, este filosofo distingue entre la retórica y la analítica.

La argumentación es "un proceso que implica: una interacción discursiva entre interlocutores, y la utilización y producción de un texto lingüístico. Este proceso podría ser definido como social, cognitivo y lingüístico. Pero, creemos que es ante todo un proceso retórico, basado en la lógica de lo probable" (Carrillo, 2007, p. 296).

La argumentación no sólo se da exclusivamente a través de medios lingüísticos en cuyo caso se denomina argumentación monomodal, sino también puede darse por otros medios como los visuales, gestuales, proxémicos, entre otros más, que incluso se pueden combinar con los lingüísticos, es decir, con distintos medios como en la argumentación jurídica, teatral o fílmica y en cuyo caso se denomina argumentación polimodal, es justamente por estos matices que es mejor entender a la argumentación como una construcción o estructura lingüística, pero que se une al proceso cognitivo que representa a la realidad.

\section{Resultados y discusión}

En las dos variables de la investigación se obtuvo los siguientes resultados: 


\section{Niveles de la redacción científica de los estudiantes de derecho}

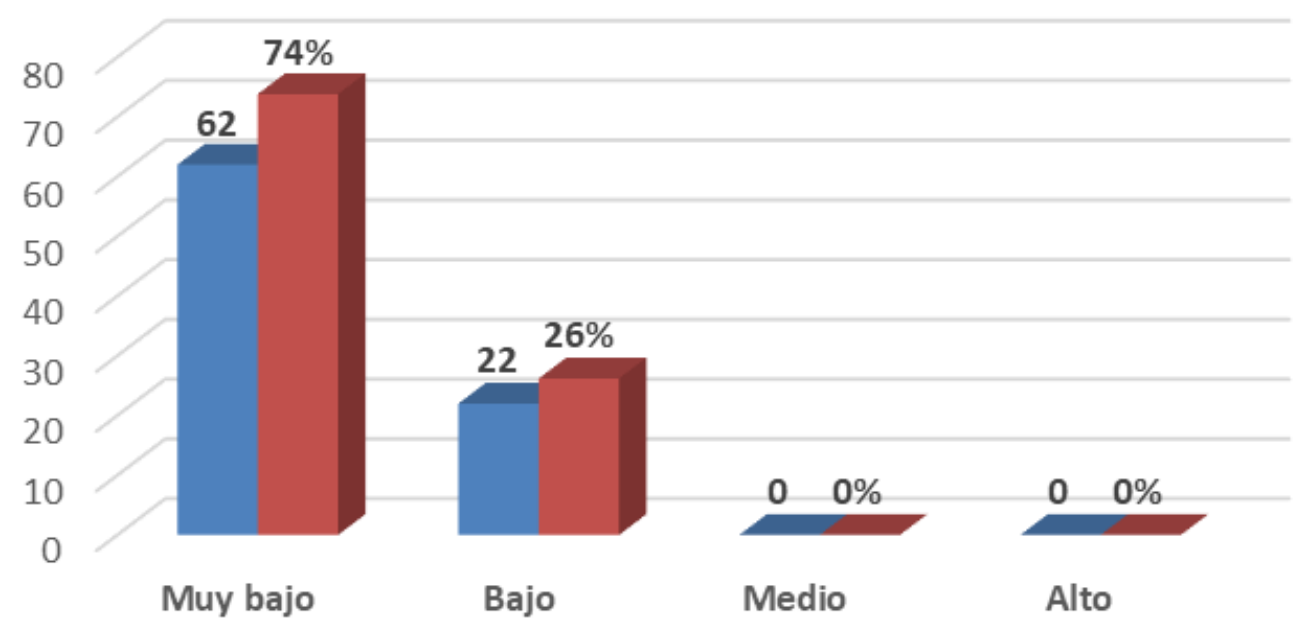

Figura 1: Niveles de redacción científica de los estudiantes de derecho.

Sobre la variable redacción científica en los estudiantes del octavo ciclo, noveno ciclo de la carrera de derecho de la Universidad Nacional de San Martin, se aprecia que el $74 \%$ se ubica en un nivel muy bajo de sus competencias en redacción; luego el $26 \%$ ocupa un nivel bajo de esta competencia. Ninguno de los sujetos investigados se ubica en el nivel medio y nivel alto. Los estudiantes no han desarrollado las capacidades de redacción científica como es el uso de términos con significado pertinente a la disciplina científica con apego y respeto de las normas de un sistema de redacción científica, sea en el nivel en que se encuentren y a lo largo de su formación académica. es decir, carecen de actividad discursiva que se refiere al razonamiento empleado en disputar, discutir o impugnar una opinión ajena, para probar o demostrar una proposición propia, o bien para convencer a alguien de aquello que se afirma o se niega a favor o en contra de algo relacionado con el derecho; el resto $29 \%$ tiene un nivel bajo. Ninguno en el nivel medio y alto sobre la argumentación jurídica, lo que indica no con menos preocupación que unas de las habilidades propias a las competencias necesarias para un futuro profesional del derecho no muestran esa requerida habilidad lingüística y oralidad para exponer sus proposiciones y defender el derecho con sustento y precisión léxica.

Sobre la argumentación jurídica, se puede observar que el $71 \%$ de los sujetos investigados tienen un nivel muy bajo de esta competencia, 


\section{Nivleles de la argumentación jurídica en estudiantes de derecho}

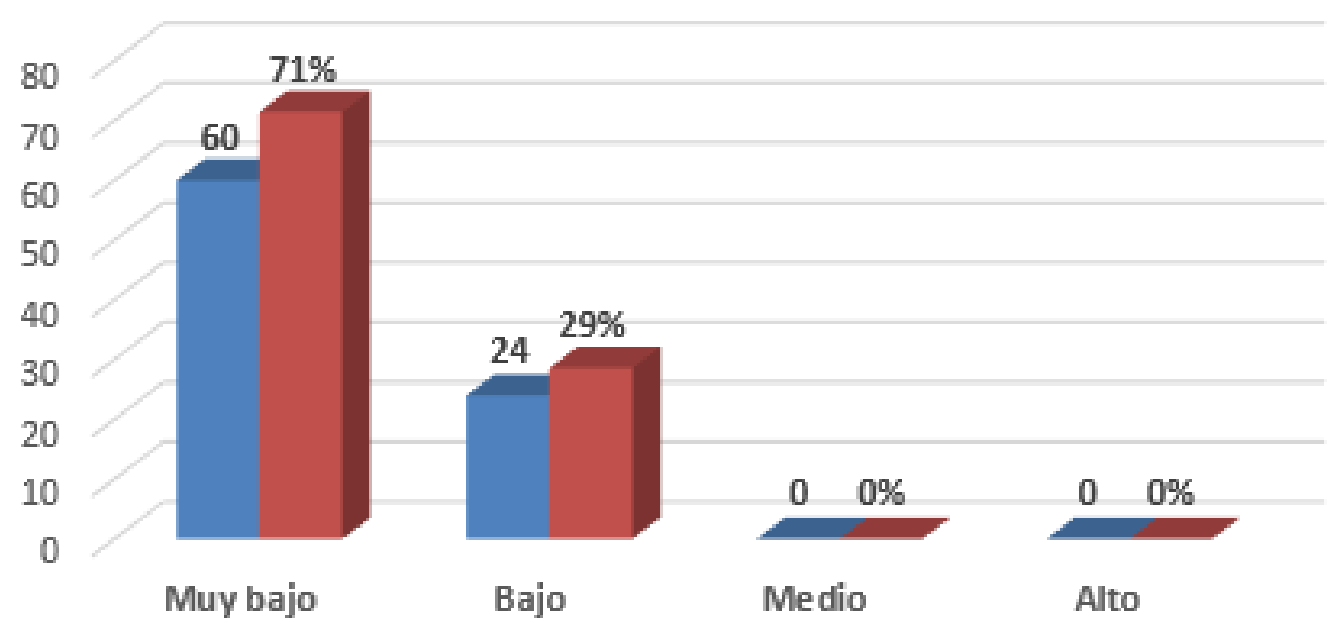

Figura 2: Niveles de Argumentación Jurídica de los sujetos en la investigación

Ubicando el resultado se tiene que rho $=0,195$, se encuentra entre el rango de $(0,10$ y 0,24$)$ lo que se ubica en la correlación considerado como correlación positiva muy débil entre la redacción científica y la argumentación jurídica los estudiantes del octavo ciclo, noveno ciclo y egresados de derecho de la Universidad Nacional de San Martin 2020. La decisión, puesto que $\mathrm{t}$ calculada es mayor que " $\mathrm{t}$ " teórica $(1,80<1,96), r(0,195)>0.10 ;$ sig. $0,76>0,05$ en consecuencia, se rechaza la hipótesis alterna (Hi) y se acepta la hipótesis nula (Ho).

\section{Tabla 1}

Correlaciones

\begin{tabular}{lllr|r}
\hline & & \multicolumn{2}{c}{$\begin{array}{c}\text { Redacción } \\
\text { Científica }\end{array}$} & $\begin{array}{c}\text { Argumentación } \\
\text { Jurídica }\end{array}$ \\
\hline Rho de & $\begin{array}{l}\text { Redacción } \\
\text { Spearman }\end{array}$ & Coeficiente de correlación & 1,000 &, 195 \\
\cline { 3 - 5 } & Científica & Sig. (bilateral) & &, 076 \\
\cline { 3 - 5 } & $\mathrm{N}$ &, 195 & 84 \\
\cline { 2 - 5 } & Argumentación & & 1,000 \\
& Jurídica & Coeficiente de correlación &, 076 & \\
\cline { 3 - 5 } & & Sig. (bilateral) & 84 & 84 \\
\cline { 3 - 5 } & $\mathrm{N}$ & & \\
\hline
\end{tabular}


Se concluye que no existe relación entre las competencias de redacción científica y argumentación jurídica en los sujetos de investigación integrados por los estudiantes del octavo ciclo, noveno ciclo y egresados de la Universidad Nacional de San Martin año 2019 2020. Es decir, $x=t c(1,80)<t(1,96)$. Se deja constancia que se adopta dicha decisión a pesar que en el resultado numérico se ha obtenido una primera existencia como relación positiva muy débil, no obstante, a consideración del investigador, siendo esta menor a 0,05 , es válido que sea considerada por su nivel de insuficiencia, como un resultado no significativo.

La presente investigación, corrobora con los datos de la población estudiada que anteceden, se evidencia en concreto la existencia de preocupantes deficiencias en los logros de aprendizaje en su formación linguiística y científica, que les impide poder afrontar, analizar y resolver un problema de naturaleza jurídica bajo bases científicas, lingüísticas y comunicativas adecuadas e idóneas, que los mismos no saben cómo identificar un problema con relevancia jurídica o qué herramientas jurídicas utilizar para su solución, también qué variables e indicadores en el ámbito del derecho pueden aplicar, plantear hipótesis jurídicas, redactar enunciados $\mathrm{y}$ argumentos claros $\mathrm{y}$ concisos y demás competencia y habilidades necesaria para un adecuado e idóneo ejercicio de esta noble profesión.

Con esta preocupante realidad, debemos reflexionar en el sentido que se requiere trabajar mucho en la modificación del currículo universitario, en la malla curricular de las facultades que forman a los profesionales del Derecho, en especial en las universidades con características similares a la objeto de estudio, ya que los estudiantes y egresados demuestran en su mayoría que vienen culminan sus estudios sin tener una debida formación en relación a las competencias materia de la presente investigación o incluso careciendo de las mismas, lo cual afecta directamente su rendimiento y ejercicio profesional, su nivel de productividad y su desarrollo como profesional competente con ciertos fundamentos en la investigación.

Por tanto, coincidimos con lo indicado con Ortiz (2016, parr.1) que refiere que bajo esa perspectiva no hace falta ser creativo o crítico para sacar altas notas, pues sólo basta dedicar algunas horas a un esfuerzo casi mecánico de memorización de códigos y leyes para asegurar un 20 de calificación. Esa idea de que es buen abogado quien sabe de memoria la letra de los códigos y leyes debe ser desterrada de la docencia universitaria. En igual sentido Valdivia (2018, parr.3) cuando manifiesta que se sigue enseñando en muchas facultades de Derecho de la misma manera en que hace 200 
años o más (sino es que más de 500 años incluyendo a Europa) se enseñaba y se sigue evaluando el conocimiento de los alumnos por medio de exámenes escritos que, según los expertos en pedagogía, ya no proporcionan la certeza de si el alumno aprendió o no, sino que a lo sumo de que tienen buena memoria, memoria que a corto plazo es la única favorecida un poco más que la inmediata pero que a largo plazo no registra nada permanente.

La correlación baja de 1,95 de rho de Speraman al 0,05 de significancia nos permite demostrar que estas variables de la redacción científica y la argumentación jurídica en los estudiantes no se corresponden de manera directa, es decir, si un estudiante tiene desarrollada la capacidad de argumentación jurídica, no necesariamente tenga un buen desempeño en la redacción científica, ya que no es enteramente vinculante.

\section{Conclusiones}

La investigación determinó que, no existe relación significativa entre las competencias de redacción científica y argumentación jurídica en los estudiantes del octavo ciclo, noveno ciclo y egresados de Derecho de la Universidad Nacional de San Martin año 2019 - 2020, correlación de rho Spearman 0,195, nivel de significancia $0,05 \mathrm{p}$-valor $=0,76$. (se rechaza la hipótesis alterna y se acepta la hipótesis nula ante una correlación positiva muy débil).
El $73 \%$ se ubica en un nivel muy bajo de sus competencias en redacción científica, lo cual quiere decir que en líneas generales los estudiantes no han desarrollado las capacidades de redacción científica como es el uso de términos con significado pertinente a la disciplina científica, sea en el nivel en que se encuentren y a lo largo de su formación académica.

El $71 \%$ de los estudiantes en la investigados tienen un nivel muy bajo, es decir, carecen de actividad discursiva referido al razonamiento empleado en disputar, discutir o impugnar una opinión ajena, para probar o demostrar una proposición propia, o bien para convencer a alguien de aquello que se afirma o se niega a favor o en contra de algo relacionado con el Derecho.

\section{Referencia bibliográfica}

Carrillo Guerrero, L. (2007). Argumentación y Argumento. Universidad de Granada, España. UNED. Revista Signa16 (2007), págs. 289-320. Recuperado de http://revistas.uned.es/index.php/sign a/article/view/6159/5892

Hernández Sampieri, R., Fernández Collado, C., y Baptista Lucio, M. (2010) Metodología de la investigación. $5^{\circ}$ Edición. Editorial Mc Graw Hill. Interamericana. Editores S.A. de C.V. México. 
León Pastor, R. (2016). Manual de documentos propios de la redacción Fiscal. Consultado el 16 de agosto del 2019. Recuperado de: https://www.mpfn.gob.pe/Docs/0/files/ publicacion_manual_de_redaccion.pdf

Mari Mut J. (2010) Cómo escribir y publicar trabajos científicos. $R . \quad B$. MCKERROW. Recuperado de: http://grad.uprm.edu/fundamredcie nt.pdf

Ortiz Gaspar, D. A. (2016): “Una lectura crítica de la enseñanza del Perú”. Lima. Recuperado de: https://legis.pe/unalectura-critica-de-la-ensenanza-delderecho-en-el-peru/

Rojas Cairampoma, M. (2006) Manual de Redacción científica. Fondo editorial
Universidad Nacional Mayor de San Marcos. Lima. Perú.

Valdivia Reynoso, J. P. (2018): Una mirada crítica y propuesta a la enseñanza y aprendizaje del Derecho en el Perú. Lima. Recuperado de: https://www.enfoquederecho.com/201 8/03/22/una-mirada-critica-ypropuesta-a-la-ensenanza-yaprendizaje-del-derecho-en-el-peru/

Wenger Calvo, R. (2015), Teoría de la Argumentación, retórica y hermenéutica. Recuperado de: https://www.google.com/search?sxsrf= ACYBGNS64LGcgocnPMArVKfczl5 1JDE4iw\%3A1568841867610\&ei=i6 CCXZf1JNHAsA 